\title{
International Teaching and Research in Hypertext
}

\author{
Claus Atzenbeck* \\ Jaesook Cheong \\ claus.atzenbeck@iisys.de \\ jcheong@iisys.de \\ Hof University \\ Institute for Information Systems \\ Hof, Germany
}

\begin{abstract}
This paper presents a way for the hypertext community to gain strength and contribute to other fields of research by joining forces. It discusses the challenges that need to be addressed with respect to geographically scattered students and scholars, interdisciplinary courses, and students with various foreknowledge. We propose the INTR/HT project, a platform that aims for bringing hypertext scholars and students together worldwide. The interdisciplinary approach fosters creativity in the context of hypertext and is valuable for educating and supporting the next generation of hypertext scholars and researchers.
\end{abstract}

\section{CCS CONCEPTS}

- Social and professional topics $\rightarrow$ Computer science education; $\bullet$ General and reference $\rightarrow$ Surveys and overviews; $\bullet$ Applied computing $\rightarrow$ Distance learning; $\bullet$ Human-centered computing $\rightarrow$ Hypertext / hypermedia.

\section{KEYWORDS}

hypertext, hypertext community, research, projects, university teaching, distance teaching, didactic, hypertext systems, INTR/HT, Historic Hypertext Project

ACM Reference Format:

Claus Atzenbeck and Jaesook Cheong. 2021. International Teaching and Research in Hypertext. In Proceedings of the 32nd ACM Conference on Hypertext and Social Media (HT '21), August 30-September 2, 2021, Virtual Event, Ireland. ACM, New York, NY, USA, 6 pages. https://doi.org/10.1145/3465336.3475124

\section{INTRODUCTION}

Hypertext is a term that is very much associated with the World Wide Web, the most dominant distributed system we currently use. In particular, some basic paradigms play an essential role in people's perception of hypertext. Among the most important is the Uniform Resource Identifier (URI) [6], which most people would call "a link" in the context of the Web. For example, if one requests "the link to a website", nothing else but the URI to the respective Web document

${ }^{*}$ Corresponding author

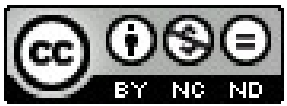

This work is licensed under a Creative Commons Attribution-NonCommercialNoDerivs International 4.0 License.

HT '21, August 30-September 2, 2021, Virtual Event, Ireland.

(C) 2021 Copyright held by the owner/author(s).

ACM ISBN 978-1-4503-8551-0/21/08.

https://doi.org/10.1145/3465336.3475124 would be expected. Our thinking and our use of language is heavily influenced by the Web.

Even though the Web boosted use and popularity of hypertext paradigms worldwide, other hypertext topics or the "original" hypertext community [37] could not follow up equally. This can be experienced by looking at the ACM Hypertext Conference series ${ }^{1}$. Over the span of several decades some research communities that used to be part of hypertext lost their connection to the hypertext community, for example, the electronic literature community [12].

In recent ACM Hypertext conferences, data analytics [4, 26, 35] became a popular topic. Only few "original" hypertext topics remained, such as hypertext system infrastructures $[15,23]$ or hypertext in electronic literature [22, 28]. The danger of hypertext losing its unique selling point and getting absorbed by larger communities became realistic.

The $30^{\text {th }}$ anniversary ACM Conference on Hypertext and Social Media (which took place in Hof, Germany, in 2019) aimed for reversing this trend. With its motto "tear down the wall" the conference aimed for teaming up again with communities that show a strong focus on hypertext.

This paper presents the project International Teaching and Research in Hypertext ${ }^{2}$ (INTR/HT) as another approach for strengthening the hypertext community and its topics. Section 2 explains the overall aim of the project. Section 3 and 4 discuss the challenges we currently face and corresponding solutions to those. Section 5 describes another related project, The Historic Hypertext Project (hist_HT). Finally, Section 6 concludes this paper and provides some thoughts about future developments in this field.

\section{AIMS}

The INTR/HT project was initiated to establish a network of hypertext researchers or relevant organizations. Its aim is strengthening and fusing various facets of hypertext research and teaching. Even though the Web is huge, "traditional" hypertext is a niche topic. Nevertheless, as it cultivates a paradigm that is related to humans and computers likewise, hypertext is also a topic that intersects with many other research areas and application domains. Thus, it is natural that researchers dealing with hypertext are active in various communities, reaching from rather "traditional" hypertext (e.g., electronic literature, HCI, or hypertext infrastructures) to less obvious ones (e.g., AI, recommender systems).

This wide spread of hypertext researchers and scholars makes cooperating difficult. As a result, this niche topic stays geographically

\footnotetext{
${ }^{1}$ https://dl.acm.org/conference/ht/proceedings

${ }^{2}$ https://intr-ht.iisys.de/
} 
fragmented, whereas topics on the raise form larger communities. This development can be witnessed over the past decades. Hypertext research, however, proposes a paradigm which turns out to be beneficial in many contexts. Building a network of hypertext scholars seems to be the first step to take, when we want hypertext to be more widely recognized in academia or industry. Such a network should be capable of:

(1) Connecting complementary research fields of hypertext;

(2) Supporting hypertext researchers in identifying colleagues whose work may be complementary to theirs;

(3) Helping scholars to identify topics or repositories containing course material for teaching hypertext classes;

(4) Acting as a starting point for scholars for designing joint courses;

(5) Serving as a first step toward a hypertext manifesto that is widely accepted by the community as a common understanding of what hypertext is.

Overall, the hypertext community would gain from increasing their visibility in other fields or connectivity to other topics. It would "export" its topics to be considered in other research areas. Furthermore, it would include other fields to improve hypertext research and applications [5].

The overall goal of an increased visibility of hypertext topics and availability of relevant resources can be achieved in the mid or long term by the following actions:

(1) Teaching foundations of hypertext in specific courses or as part of related courses;

(2) Getting students to be interested in hypertext;

(3) Raising students to become eventually hypertext researchers, including supporting them in writing their bachelor, master, or dissertation theses in this field;

(4) Collaborations between hypertext researchers with respect to (i) building up repositories of teaching material; (ii) designing joint courses towards rich and complementary contents for students; (iii) supporting student exchange programs with a focus on hypertext; and (iv) referring students or graduates to open research positions in the field of hypertext.

The INTR/HT project aims for the above-mentioned goals by implementing the described actions. The following section will discuss the challenges related to those.

\section{CHALLENGES}

\subsection{Overview}

As presented in the previous section, there are various actions to take toward a dense network of hypertext scholars and joint courses. This opens a number of challenges that we face, including:

(1) Sparsely located hypertext scholars and courses;

(2) Scattered conferences and various topics in which hypertext plays a role;

(3) Few commonly accessible repositories with hypertext teaching material;

(4) Scholars lacking knowledge of other, possibly interdisciplinary courses that would enhance their own hypertext courses ("horizontal" perspective);
(5) Students of various levels, including bachelor, master, or Ph.D. level ("vertical" perspective).

In the following, we will discuss these issues in greater detail.

\subsection{Geographically Sparse Scholars, Courses, and Conferences}

Hypertext scholars are geographically scattered. As a consequence, students interested in hypertext often have limited learning opportunities at their own university. Classes are mostly taught in presence at their respective universities (except during the pandemic). This hinders communication and international cooperation in teaching. It is likely that scholars know their colleagues' research interests from meetings, conferences, or from reading their publications. However, they may not have a sufficiently good picture of who is teaching hypertext relevant topics and has an interest in contributing to a network or would like to support student exchange activities.

Joint courses offered by geographically scattered universities may also face language problems, if students from different countries are involved. This can be easily fixed by having all students agree on a common course language (e.g., English). If this is not possible, for example, because a university's curriculum requires a specific language in class, the cooperation must be adjusted accordingly. For instance, synchronous teaching (e.g., using live video streaming) would not be possible in a usual way. Cultural differences between course participants may also affect teaching or learning experiences, which can be challenging.

Cooperations in teaching must also consider various time zones. For example, for students located in Boston (USA, UTC-5), Berlin $($ Germany, UTC+1), and Yokohama (Japan, UTC+9) synchronously taught lectures may turn out to be a problem: a common time slot that fits all students' preferences may hardly be found. This limits the possibilities in setting up synchronous lectures, which has an effect on the didactic methods to be selected.

\subsection{Scattered Hypertext Conferences and Topics}

As mentioned already in the previous section, hypertext is a topic that addresses or can be found in various other fields, including AI, recommender systems, literature, philosophy, etc. There are only a few conferences addressing hypertext as their main topic, for example, the ACM Hypertext Conference series (since 1987). Nevertheless, valuable hypertext research may also be found in other fields.

In order to provide a richer experience with hypertext topics, it is desirable to explicitly connect those fields and represent them in a single accessible knowledge graph. Such information is valuable for (i) researchers searching for cooperation partners; (ii) scholars wishing to improve or extend their hypertext courses with respect to content or organization issues; (iii) students aiming for more information about specific topics, not being aware of the fact that hypertext is relevant to them; and (iv) students planning to visit other universities, where courses most relevant to their interest or complementary to their background are offered.

Furthermore, such a common knowledge structure will present hypertext well for collaborations across different fields and cultures. 
Hypertext is an interdisciplinary topic, and interdisciplinarity is an essential breeding ground for creativity.

\subsection{Lacking Common Hypertext Teaching Repositories}

There are textbooks or standard literature for many topics taught in university classes. For example, for computer science there are textbooks about formal languages [16], operating systems [33], various programming languages [10], algorithms and data structures [9], or databases [27]. Those are examples of fundamental topics, essential for computer science curricula. Furthermore, many of them are rather longstanding topics. The same can be witnessed in any other academic fields.

On the contrary, we are lacking recent hypermedia textbooks that discuss a wide range of hypertext topics. This is most likely caused by the fact that hypertext has changed from a "big" topic to a cross-sectional topic (while still remaining to be the underlying paradigm of the Web). There are, however, publications about hypertext (e.g., conference papers or journal articles), addressing various fields of research. Furthermore, hypertext scholars themselves own teaching assets which they frequently use for their students, including reading lists or lecture notes.

Scholars would benefit from a global repository of hypertext teaching material, including reading lists, publications, lecture notes, or lecture videos. This could be used for improving current lectures or creating new ones. It also helps them in teaching or designing joint classes. Such a repository requires to classify its content, for example, with respect to the required level of foreknowledge, the field of research, or connections to other relevant assets or information sources.

In particular, the associations between assets may help experts to find valuable connections between different, interdisciplinary topics or active colleagues in the respective fields. The envisioned knowledge graph can also be used by machines, such as recommender systems, to propose relevant topics, experts, or (to students) universities for further studies.

\subsection{Students' Foreknowledge and Courses of Studies}

Another challenge relates to the different levels students may have. For example, a hypertext course (or a course which includes hypertext topics) may use different contents or level of depths for bachelor, master, or Ph.D. students. This makes the course more flexible and open to students with different foreknowledge or study levels. This is likely to happen in interdisciplinary courses. For example, a computer science student is likely to have a better understanding of hypertext infrastructures compared to an economics student, who may, in turn, have better knowledge about the economical or social impact of hypertext technologies in companies.

Having students with different expertise and foreknowledge joining the same course, however, raises some issues related to didactic or teaching methods. This can be turned into new opportunities for learning. For example, more advanced students may reach a higher level of understanding by helping beginners. This interdisciplinary approach can be considered as a means for further extending the hypertext community.

\subsection{Didactic}

The previous sections mention didactic and teaching methods several times, undoubtedly an important aspect when it comes to teaching. The presented challenges must be addressed by carefully selecting appropriate means of teaching. Those depend on the course or collaboration characteristics and have to be decided separately for each course. The proposed network of hypertext scholars and repository of teaching assets may act as building blocks for designing courses and introducing novel and innovative ways of teaching. The following section presents some solutions related to the discussed challenges.

\section{SOLUTIONS}

\subsection{Collaboration Tools}

The goal of the project International Teaching and Research in Hypertext (INTR/HT) is to develop solutions to the problems described in the previous section. A requirement of joint courses of geographically scattered students and lecturers is a platform supporting (i) learning at an individual pace; (ii) learning with different levels of knowledge; (iii) studying with flexibility of time and place; (iv) supporting different types of communication and exchange of information; (v) providing scalable courses across multiple universities; (vi) learning in international contexts; (vii) promoting hypertext topics; and (viii) supporting young scientists starting their work in the field of hypertext.

For such a platform, Learning Management Systems (LMS) such as Moodle ${ }^{3}$ are the first option to consider. Those systems use hypertext paradigms to the level well known in industry. However, in hypertext courses, it would be beneficial for students to use hypertext systems that are state-of-the-art in research and, thus, go beyond of what we know from today's products.

For example, Weblinks [29], developed at Hof University, is a browser plugin which enables users to set links between arbitrary Web pages. Based on a feature subset of the Dexter Hypertext Reference Model [14], Weblinks supports link directions (uni or bidirectional) and $n$-ary links. Another example is the componentbased hypermedia system Dash [38], developed at Brown University, featuring transclusion of documents and views. Dash supports synchronous and asynchronous collaboration, which is in particular relevant for university courses.

Using such systems for learning would be beneficial not only for students, but also for lecturers and hypertext researchers. Lecturers would be given additional tools to ease structuring of teaching assets. Researchers would have a chance of gaining new insights about their hypertext tools by experiencing and evaluating their tools in practice. Furthermore, the use of novel tools would present and promote hypertext topics to students, scholars, and potentially the industry.

\subsection{Ways of Teaching}

In order to effectively achieve the stated goals and target related challenges, we need to employ didactic principles accordingly. Technologies in education are basic building blocks for courses, supporting scalability across multiple universities or study programs, and

\footnotetext{
${ }^{3}$ https://moodle.com/lms/
} 
embracing differences in students' backgrounds better. It is important to notice that technology in education does not only refer to the transition of presence teaching toward live video streaming (as this happened in a large scale during the COVID-19 pandemic) or just setting up another MOOC $^{4}$ course. Instead, technology in education demands overall new didactic concepts, including synchronous (e.g., face-to-face) and asynchronous (e.g., using videos) teaching. Those concepts may be based on various learning theories, including cognitivism, constructivism, and (in particular) connectivism [3, 32]. More details on learning theories can be found in [17].

Teaching methods such as flipped classroom $[1,36]$ or blended learning [19] allow students studying at their own pace. In those methods, students study a manageable amount of learning topics before class using provided learning material (e.g., videos, texts, or interactive content). In face-to-face meetings (i.e., synchronous teaching), the lecturer takes over the role of a coach, guiding students to solve problems by answering questions or leading discussions. This allows students with different levels of knowledge to study more effectively at their individual level.

Additionally, students may still attend lectures physically in their respective universities, possibly extended with video streaming. Scholars involved in INTR/HT may also apply for $3^{\text {rd }}$ party funding (e.g., via Erasmus ${ }^{5}$ programs) in order to open possibilities for exchanging students among participating universities.

Because INTR/HT targets international teachers and students with different backgrounds, courses must consider this accordingly. Beyond that, the didactic concept for setting up such courses should support competency-based learning [11,20], helping students in enhancing certain skills, such as (i) foreign languages; (ii) effective communication; (iii) interdisciplinary cooperation; (iv) interpersonal skills by working in intercultural teams; (v) self-driven and independent planning; and (vi) personal responsibility for archiving goals.

\subsection{Example Course}

The idea in INTR/HT is to start with small teams. This eases experimenting with new didactic methods. The focus is on a few first courses that provide valuable feedback to be used during a later up-scaling phase. Additionally, the use of hypertext tools provides data and feedback that opens possibilities for improvements in larger courses. In this section we present an example course and its unique features provided by INTR/HT.

Imagine a joint INTR/HT course which includes students of three different universities, further described in Tab. 1. As mentioned earlier, such "patchwork courses" may be set up with different courses of study and multiple levels of study. Furthermore, we may also consider courses only partly joining in for specific topics.

For this imagined INTR/HT course, students in the economics class are only interested in a few specific topics, such as four lectures on the history of the Web. Likewise, the students in the literature class are interested in ten lectures, in which they discuss hypertext as a medium used in the electronic literature domain. The computer science (CS) students attend a course that is fully dedicated to

\footnotetext{
${ }^{4}$ Massive Open Online Course. This became popular around 2012 [25], gaining in popularity during the COVID-19 pandemic [18].

${ }^{5}$ European Community Action Scheme for the Mobility of University Students, https: //ec.europa.eu/programmes/erasmus-plus/
}

hypertext. As Tab. 1 shows, students' background knowledge and level of education differ.

The INTR/HT course must be designed to match the topics and time frames of the various participating courses. For example, all three courses may use material, joint synchronous discussions, or group exercises for Web-related course contents. Course material is provided by a shared repository, such that the individual lecturers can select what is most appropriate for their respective courses. In addition, the CS and the literature courses got some funding from a student exchange program, which allows them to spend some weeks abroad as guest students.

It is beneficial to define student groups interdisciplinary, because with complementary foreknowledge and skills, group members can learn from each other and look at learning contents from different perspectives. Another goal of this INTR/HT course is a virtual student conference, with students presenting their projects. Submitted student papers may be reviewed by the students themselves. Even though the economics students cannot contribute much to the literature or CS students' study content, as M.Sc. level students, they are more experienced in how a "research paper" should be written. Thus, they can contribute by supervising others in that respect. The same is true, for example, for $5^{\text {th }}$ semester CS students advising $3^{\text {rd }}$ semester literature students in computer systems related topics.

At the end of the INTR/HT course, students will present their work. Possibly even awards (such as best paper awards) may be given, which can be an additional incentive for students to engage in the course.

Because the INTR/HT course is a "virtual layer" on top of formal courses, the performance of the students has to be assessed individually by their respective universities. Examinations may include outcomes from the INTR/HT course, such as students' papers. In other cases, other types of examination, such as written exams, may be more appropriate.

\section{THE HISTORIC HYPERTEXT PROJECT}

The Historic Hypertext Project ${ }^{6}$ (hist_HT) is a special part of INTR/ HT. This project aims at collecting and running historic hypertext systems in virtual machines and providing information about their functionalities and technologies. This preserves vintage hypertext systems for coming generations of students and scholars, likewise. For example, systems of interest include (but are not limited to) HyperTIES [31], VKB [30] (both already installed), KMS [2], NoteCards [13], Intermedia [24], Guide [7], HyperCard [34], and Viki [21], as well as various vintage Web browsers, such as NCSA Mosaic, Arachne, or MINUET $^{7}$ (all installed).

Systems provided by hist_HT can be used in hypertext related courses to demonstrate features to students, who would otherwise only see screenshots on slides. Furthermore, lecturers may choose to provide hands-on sessions in which students can check out those applications themselves or use them for their projects. This will make students aware of beneficial features that are not common in today's Web and foster novel and creative solutions in current contexts.

\footnotetext{
${ }^{6}$ https://human.iisys.de/hist_HT/

${ }^{7}$ Minnesota Internet Users Essential Tool
} 
Table 1: Sample INTR/HT course

\begin{tabular}{lcll}
\hline Country & Semester & Course of Study & Course Title \\
\hline USA & $8^{\text {th }}$ & M.Sc. Economics & "Digital Economy" \\
Germany & $5^{\text {th }}$ & B.Sc. Computer Science & "Hypertext" \\
Greece & $3^{\text {rd }}$ & B.Sc. Literature and Arts & "Electronic Storytelling" \\
\hline
\end{tabular}

Furthermore, such systems belong to the historic foundations of various communities that deal with hypertext, such as electronic literature or HCI. Such common ground may help scholars in the respective groups to join their efforts. Also, a cooperation between hist_HT and museums or archives (e.g., electronic literature $\operatorname{archives}^{8}$ ) may lead to synergies and win-win situations.

\section{CONCLUSION AND FUTURE WORK}

In this paper, we identified the benefits for the hypertext community from joint efforts in educating students and identified related challenges. We proposed the INTR/HT project as a platform for bringing scholars and students together worldwide. It offers a virtual space to form networks for collaboration, learning, and educating the next generation of hypertext scholars and practitioners. Furthermore, we identified the hist_HT project as a beneficial companion, used in interdisciplinary teaching or research contexts.

We discussed the strong demand for digitalization in INTR/ HT courses in order to support (i) collaborating geographically scattered students and scholars; (ii) interdisciplinary courses; and (iii) students with different education level or background knowledge. This diversity fosters creativity in the context of hypertext. The use of current (research) hypertext applications in classes provide students with state-of-the-art tools to experiment with and researchers receiving evaluation data for their prototypes. In order to benefit most, we suggest to approach novel didactic forms of teaching, for which applied hypertext paradigms may be helpful in supporting "thinking and communication" [8].

In the future, INTR/HT may be extended in various ways, building up a bigger picture of hypertext and strengthening the hypertext community. This includes extending the view toward hypertext scholarship, research topics, and their relations to state-of-the-art teaching. Furthermore, appropriate research approaches must be developed and scenarios described, considering interdisciplinary work from various hypertext-relevant fields, such as didactic, psychology, or linguistics.

Developing concrete scenarios based on hypertext technologies helps to sharpen curricula, to enhance learning outcomes, and to discover relevant future research topics. From these scenarios, scholars can identify appropriate teaching methods, select effective means of communication, or suggest/develop better tools.

INTR/HT provides universities with the potential of new collaborations or curricula. Some courses (based on novel didactic methods) may be even designed for high quality online-only teaching. Overall, following the proposed approach, the hypertext community has the chance to strengthen the interdisciplinary nature of its topics,

\footnotetext{
${ }^{8}$ See, for example, https://eliterature.org/electronic-literature-archives/
}

draw more interested students, raise a larger number of young scholars/researcher, and influence other related fields of research.

\section{ACKNOWLEDGMENTS}

The INTR/HT project is funded by the Bavarian State Ministry of Science and the Arts (grant ID "Kapitel 1549 TG 73"). This publication was also supported by Freunde und Förderer der Hochschule Hof (grant ID “Digitalization in University Teaching Award 2018”).

\section{REFERENCES}

[1] Lakmal Abeysekera and Phillip Dawson. 2015. Motivation and cognitive load in the flipped classroom: definition, rationale and a call for research. Higher Education Research \& Development 34, 1 (2015), 1-14. https://doi.org/10.1080/ 07294360.2014 .934336

[2] Robert M. Akscyn, Donald L. McCracken, and Elise A. Yoder. 1988. KMS: a distributed hypermedia system for managing knowledge in organizations. Commun. ACM 31, 7 (1988), 820-835. http://doi.acm.org/10.1145/48511.48513

[3] Alaa A. AlDahdouh, António J. Osório, and Susana Caires. 2015. Understanding knowledge network, learning and connectivism. International fournal of Instructional Technology and Distance Learning 12, 10 (2015), 3-21. https: //itdl.org/Journal/Oct_15/Oct15.pdf

[4] Nikolaos Aletras and Benjamin Paul Chamberlain. 2018. Predicting Twitter User Socioeconomic Attributes with Network and Language Information. In Proceedings of the 29th on Hypertext and Social Media. ACM, 20-24. https: //doi.org/10.1145/3209542.3209577

[5] Claus Atzenbeck and Peter Nürnberg. 2019. Hypertext as Method. In Proceedings of the 30th ACM Conference on Hypertext and Social Media (HT '19). ACM, 29-38. https://doi.org/10.1145/3342220.3343669

[6] Tim Berners-Lee, R. Fielding, and L. Masinter. 2005. Uniform Resource Identifier (URI): Generic Syntax. Technical Report. Internet Engineering Task Force. https: //datatracker.ietf.org/doc/html/rfc3986/

[7] P. J. Brown. 1987. Turning ideas into products: the Guide system. In Proceedings of the ACM Conference on Hypertext. ACM, 33-40. http://doi.acm.org/10.1145/ 317426.317430

[8] Jeff Conklin. 1987. Hypertext: an introduction and survey. Computer 20, 9 (1987), 17-41. http://dx.doi.org/10.1109/MC.1987.1663693

[9] Thomas H. Cormen, Charles E. Leiserson, Ronald L. Rivest, and Clifford Stein. 2009. Introduction to Algorithms (3 ed.). MIT Press.

[10] David J. Eck. 2019. Introduction to Programming Using Java (version 8.1 ed.). Hobart and William Smith Colleges. http://math.hws.edu/javanotes

[11] Glossary of Education Reform. 2014. Competency-Based Learning Definition. https://www.edglossary.org/competency-based-learning/

[12] Dene Grigar. 2019. Tear Down the Walls: An Exhibition of Hypertext \& Participatory Narrative. In Proceedings of the 30th ACM Conference on Hypertext and Social Media. ACM, 1. https://doi.org/10.1145/3342220.3345459

[13] Frank G. Halasz, Thomas P. Moran, and Randall H. Trigg. 1987. NoteCards in a nutshell. In Proceedings of the SIGCHI/GI Conference on Human Factors in Computing Systems and Graphics Interface (CHI '87). ACM Press, 45-52. http: //doi.acm.org/10.1145/29933.30859

[14] Frank G. Halasz and Mayer Schwartz. 1994. The Dexter Hypertext Reference Model. Commun. ACM 37, 2 (2 1994), 30-39. http://doi.acm.org/10.1145/175235. 175237

[15] Charlie Hargood, Mark J. Weal, and David E. Millard. 2018. The StoryPlaces Platform: Building a Web-Based Locative Hypertext System. In Proceedings of the 29th on Hypertext and Social Media. ACM, 128-135. https://doi.org/10.1145/ 3209542.3209559

[16] John E. Hopcroft, Rajeev Motwani, and Jeffrey D. Ullman. 2011. Einführung in Automatentheorie, Formale Sprachen und Berechenbarkeit (3 ed.). Pearson Studium.

[17] Ronghuai Huang, J. Michael Spector, and Junfeng Yang. 2019. Educational Technology: A Primer for the 21st Century. Springer, Singapore. 
[18] Chris Impey and Martin Formanek. 2021. MOOCS and 100 Days of COVID: Enrollment surges in massive open online astronomy classes during the coronavirus pandemic. Social Sciences \& Humanities Open (2021), 100177. https: //doi.org/10.1016/j.ssaho.2021.100177

[19] Kevin Lothridge, Jamie Fox, and Eileen Fynan. 2013. Blended learning: efficient, timely and cost effective. Australian fournal of Forensic Sciences 45, 4 (2013), 407-416. https://doi.org/10.1080/00450618.2013.767375

[20] Miltiadis D. Lytras, Patricia Ordonez De Pablos, David Avison, Janice Sipior, Qun Jin, Walter Leal Filho, Lorna Uden, Michael Thomas, Sara Cervai, and David G. Horner (Eds.). 2010. Technology Enhanced Learning: Quality of Teaching and Educational Reform. Proceedings of the 1st International Conference, TECHEDUCATION. Springer.

[21] Catherine C. Marshall, Frank M. Shipman, and James H. Coombs. 1994. VIKI Spatial hypertext supporting emergent structure. In Proceedings of the 1994 ACM European Conference on Hypermedia Technology. ACM Press, 13-23. http://doi. acm.org/10.1145/192757.192759

[22] Stacey Mason and Mark Bernstein. 2019. On Links: Exercises in Style. In Proceedings of the 30th ACM Conference on Hypertext and Social Media. ACM, 103-110. https://doi.org/10.1145/3342220.3343665

[23] Alexander Mehler, Giuseppe Abrami, Christian Spiekermann, and Matthias Jostock. 2018. VAnnotatoR: A Framework for Generating Multimodal Hypertexts. In Proceedings of the 29th on Hypertext and Social Media. ACM, 150-154. https://doi.org/10.1145/3209542.3209572

[24] Norman Meyrowitz. 1986. Intermedia: The architecture and construction of an object-oriented hypemedia system and applications framework. ACM SIGPLAN Notices 21, 11 (1986), 186-201. http://doi.acm.org/10.1145/960112.28716

[25] Laura Pappano. 2012. The Year of the MOOC. The New York Times (Nov 2012).

[26] Jasabanta Patro and Pushpendra Singh Rathore. 2020. A Sociolinguistic Route to the Characterization and Detection of the Credibility of Events on Twitter. In Proceedings of the 31st ACM Conference on Hypertext and Social Media. ACM 241-250. https://doi.org/10.1145/3372923.3404795

[27] Raghu Ramakrishnan and Johannes Gehrke. 2003. Database Management Systems (3 ed.). McGraw-Hill

[28] Jill Walker Rettberg, Marianne Gunderson, Linda Kronman, Ragnhild Solberg, and Linn Heidi Stokkedal. 2019. Mapping Cultural Representations of Machine Vision: Developing Methods to Analyse Games, Art and Narratives. In Proceedings of the 30th ACM Conference on Hypertext and Social Media. ACM, 97-101. https: //doi.org/10.1145/3342220.3343647
[29] Daniel Roßner, Claus Atzenbeck, and Daniel Urban. 2020. Weblinks: Augmenting Web Browsers with Enhanced Link Services. In Proceedings of the 3rd Workshop on Human Factors in Hypertext. ACM, Article 5, 5 pages. https://doi.org/10.1145/ 3406853.3432663

[30] Frank M. Shipman, Robert Airhart, Haowei Hsieh, Preetam Maloor, J. Michael Moore, and Divya Shah. 2001. Visual and spatial communication and task organization using the Visual Knowledge Builder. In Proceedings of the 2001 International ACM SIGGROUP Conference on Supporting Group Work. ACM Press, 260-269. http://doi.acm.org/10.1145/500286.500325

[31] Ben Shneiderman. 1987. User interface design for the Hyperties electronic encyclopedia (panel session). In Proceedings of the ACM Conference on Hypertext. ACM, 189-194. http://doi.acm.org/10.1145/317426.317441

[32] George Siemens. 2005. Connectivism: A Learning Theory for the Digital Age. International Journal of Instructional Technology and Distance Learning 2, 1 (2005). https://itdl.org/Journal/Oct_15/Oct15.pdf

[33] Abraham Silberschatz, Peter B. Galvin, and Greg Gagne. 2019. Operating System Concepts (10 ed.). Wiley.

[34] Ted Smith and Steve Bernhardt. 1988. Expectations and experiences with HyperCard: a pilot study. In Proceedings of the 6th Annual International Conference on Systems Documentation (SIGDOC'88). ACM Press, 47-56. http: //doi.acm.org/10.1145/358922.358931

[35] Martino Trevisan, Luca Vassio, Idilio Drago, Marco Mellia, Fabricio Murai, Flavio Figueiredo, Ana Paula Couto da Silva, and Jussara M. Almeida. 2019. Towards Understanding Political Interactions on Instagram. In Proceedings of the 30th ACM Conference on Hypertext and Social Media. ACM, 247-251. https://doi.org/ $10.1145 / 3342220.3343657$

[36] Huseyin Uzunboylu and Damla Karagözlü. 2015. Flipped classroom: a review of recent literature. World fournal on Educational Technology 7, 2 (2015), 142147. https://www.ingentaconnect.com/content/doaj/13091506/2015/00000007/ 00000002/art00005

[37] Andries van Dam. 2019. Reflections on a Half-Century of Hypertext. In Proceedings of the 30th ACM Conference on Hypertext and Social Media. ACM, 3-4. https://doi.org/10.1145/3342220.3344782

[38] Stanley Yip, Bob Zeleznik, Samuel Wilkins, Tyler Schicke, and Andries van Dam. 2020. Dash: A Hyper Framework. In Proceedings of the 31st ACM Conference on Hypertext and Social Media. ACM, 237-238. https://doi.org/10.1145/3372923. 3404807 
The data below is what we call Visual-Meta. It is an approach to add information about a document to the document itself, on the same level of the content (in style of BibTeX). It is very important to make clear that Visual-Meta is an approach more than a specific format and that it is based on wrappers. Anyone can make a custom wrapper for custom metadata and append it by specifying what it contains: for example @dublin-core or @rdfs.

The way we have encoded this data, and which we recommend you do for your own documents, is as follows:

When listing the names of the authors, they should be in the format 'last name', a comma, followed by 'first name' then 'middle name' whilst delimiting discrete authors with ('and') between author names, like this: Shakespeare, William and Engelbart, Douglas C.

Dates should be ISO 8601 compliant.

Every citable document will have an ID which we call 'vm-id'. It starts with the date and time the document's metadata/Visual-Meta was 'created' (in UTC), then max first 10 characters of document title.

To parse the Visual-Meta, reader software looks for Visual-Meta in the PDF by scanning the document from the end, for the tag @ \{visual-meta-end\}. If this is found, the software then looks for @\{visual-meta-start $\}$ and uses the data found between these tags. This was written September 2021. More information is available from https://visual-meta.info for as long as we can maintain the domain.

@\{visual-meta-start $\}$

$@\{$ visual-meta-header-start $\}$

@visual-meta $\{$ version $=\{1.1\}$

generator $=\{$ ACM Hypertext 21$\}$,

organisation $=\{$ Association for Computing Machinery $\}$,

@\{visual-meta-header-end\}

@\{visual-meta-bibtex-self-citation-start $\}$

@inproceedings $\{10.1145 / 3465336.3475124$

author $=\{$ Atzenbeck, Claus and Cheong, Jaesook $\}$

title $=\{$ International Teaching and Research in Hypertext $\}$,

year $=\{2021\}$,

isbn $=\{978-1-4503-8551-0\}$

publisher $=\{$ Association for Computing Machinery $\}$

address $=\{$ New York, NY, USA $\}$

url $=\{$ https://doi.org/10.1145/3465336.3475124\},

doi $=\{10.1145 / 3465336.3475124\}$

abstract $=\{$ This paper presents a way for the hypertext community to gain strength and contribute to other fields of research by joining forces. It discusses the challenges that need to be addressed with respect to geographically scattered students and scholars, interdisciplinary courses, and students with various foreknowledge. We propose the INTR/HT

project, a platform that aims for bringing hypertext scholars and students together worldwide. The interdisciplinary approach fosters creativity in the context of hypertext and is valuable for educating and supporting the next generation of hypertext scholars and researchers.\},

numpages $=\{6\}$,

keywords = \{hypertext; hypertext community; research; projects; university teaching; distance teaching; didactic; hypertext systems; INTR/HT; Historic Hypertext Project $\}$ location $=\{$ Virtual Event, USA $\}$,

series $=\{H T$ ' 21$\}$,

vm-id $=\{10.1145 / 3465336.3475124\}\}$

@\{visual-meta-bibtex-self-citation-end\}

@ \{visual-meta-end\} 